\title{
Imaginário do consumo: aproximações entre corpo e embalagem ${ }^{1}$
}

\author{
Tânia Márcia Cezar Hoff² \\ $\mathrm{ESPM} / \mathrm{SP}$ \\ thoff@espm.br
}

\begin{abstract}
Resumo: Neste artigo, resultado parcial de uma pesquisa a respeito do imaginário de corpo na publicidade brasileira, pretendemos discutir algumas aproximações entre corpo e embalagem, pois observamos que as representações de corpo presentes na criação publicitária apontam para a existência de um vívido diálogo com as representações de produto. Na medida em que corpo e produto se confundem, consideramos ser possível delinear um imaginário do consumo e, nele circunscrito, um consumo do corpo. A campanha publicitária das Sandálias Ipanema Gisele Bündchen, da Grendene, produzida pela agência W/Brasil, constitui o corpus que será analisado a partir de uma analogia entre embalagem e palimpsesto -- documento sobre cuja superfície muitos textos foram escritos e dos quais conserva traços imperfeitamente apagados.
\end{abstract}

Palavras-Chave: imaginário; corpo; embalagem.

Abstract: In this article, partial result of a research concerning the imaginary of body in Brazilian advertisement, we aim to discuss some approximations of body and package. We have observed that the representations of body present in advertisement creation point towards the existence of a vivid dialogue with the representations of a product. As body and product are mixed up, we consider being possible to outline an imaginary of consumption and, circumscribed within, a consumption

\footnotetext{
${ }^{1}$ Artigo apresentado no GT Tecnologias do Imaginário, no VIII Seminário Internacional da Comunicação: Mediações Tecnológicas e a reinvenção do sujeito, realizado na PUCRS em novembro de 2005.

${ }^{2}$ Doutora em Letras pela FFLCH - USP e professora do Programa de Mestrado em Comunicação e Práticas de Consumo da Escola Superior de Propaganda e Marketing $-\mathrm{ESPM} / \mathrm{SP}$.
} 
of body. The advertisement campaign of Gisele Bündchen Ipanema Sandals by Grendene, developed by the agency W/Brasil, is the corpus which will be analyzed through an analogy between package and palimpsest - a document in which one writes many times, leaving old writings poorly erased still visible.

Key words: Imaginary; body; package.

Résumé: Dans le présent article, résultat partiel d'un travail de recherche portant sur l'imaginaire du corps dans la publicité brésilienne, nous nous proposons de discuter quelques approximations entre le corps et l'emballage, car nous avons remarqué que les représentations du corps qu'on trouve dans la création publicitaire signalent l'existence d'un dialogue vivant avec les représentatiosn du produit. Dans la mesure où le corps et le produit se confondent, nous pensons qu'il est possible d'esquisser un imaginaire de la consommation et une consommation du corps qui y est circonscrite. La campagne publicitaire des sandales Ipanema Gisele Bündchen, de la compagnie Grendene, produite par l'agence de publicité W/Brasil, constitue le corpus qui sera analysé à partir d'une analogie entre emballage et palimpseste - document sur la surface duquel on a écrit à maintes reprises et où il reste des traces visibles d'écrits antérieurs effacés de manière imparfaite.

Mots-clés: imaginaire ; corps ; emballage.

Resumen: En este artículo, resultado parcial de un estudio sobre el imaginario del cuerpo en la publicidad brasileña, pretendemos discutir algunas aproximacciones entre cuerpo y envoltorio, ya que según observamos las representaciones del cuerpo presentes en la creación publicitaria señalan la evidencia de un diálogo con las representaciones del producto. En la medida en que cuerpo y producto se confunden, consideramos que es posible establecer un imaginario del consumo y, a él circunscrito, un consumo del cuerpo. La campaña publicitaria de las Sandalias Ipanema Gisele Bündchen, de la Grendene, producida por la agencia $W / B r a s i l$, constituye el corpus que será analizado a partir de una analogía entre envoltorio y palimpsesto - documento sobre cuya superficie muchas veces se ha escrito y que conserva huellas de escritos anteriores imperfectamente borrados.

Palabras-Clave: imaginario; cuerpo; envoltorio. 
Gisele Bündchen, top model brasileira de projeção internacional, aparece em campanha publicitária completamente nua e tatuada de beijaflores, tucanos, borboletas e bromélias. A imagem é de uma sensualidade quase infantil: Gisele não está nua! Revestido de elementos da fauna e da flora do Brasil, seu corpo ganha dimensões de embalagem: confere visibilidade às Sandálias Ipanema, da Grendene, e comunica o posicionamento do produto no mercado fashion. Não se trata de nudez: a top model encontra-se "vestida" de natureza brasileira transformada em apelo de consumo, conforme enuncia o novo slogan do referido produto: "Brasil à flor da pele".

Talvez pareça algo forçado ou descabido aproximar corpo e embalagem; no entanto, se atentarmos para as transformações da cultura desde o século XX até o início do XXI e para os seus impactos na concepção de tempo e espaço - e em outras que a elas se associam --, bem como na construção de subjetividades e de identidades, podemos identificar re-significações do corpo. Algumas características da cultura digital ou cibercultura, tais como, "desmaterialidade"; "desreferencialidade"; "destotalidade" e “destemporalidade" são noções explicitadas nas representações de corpo desde a arte, passando pela ciência, até a publicidade (Featherstone: 1999; Martins 2004; Santaella: 2004; Garcia: 2005; dentre outros).

Conforme afirma Wilton Garcia (2005: 159):

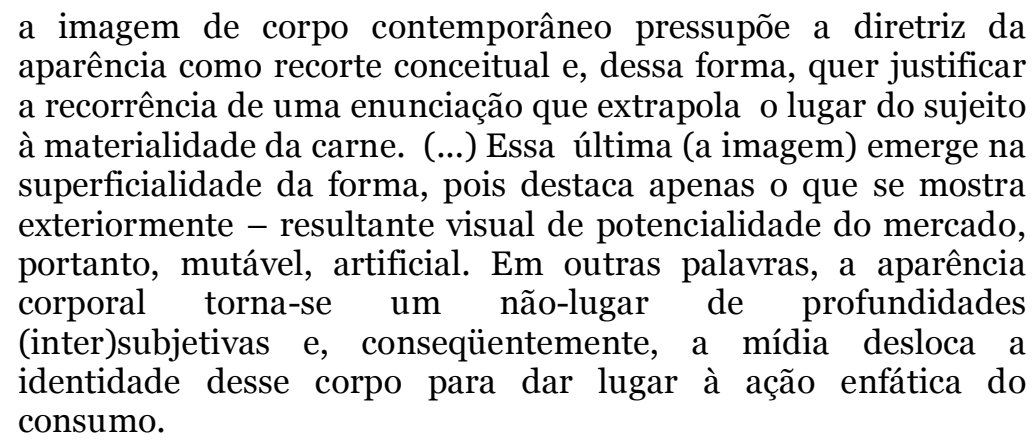

A despeito de uma possível visão apocalíptica ou disfórica dos impactos da cultura tecnológica digital, o autor alude ao fato de que a "complexa 
representação do corpo torna-se cada vez mais flexível, efêmera, provisória, inacabada, parcial” (2005:14), corroborando as reflexões de Nízia Villaça e Fred Góes na obra Em nome do corpo (1998:13): "nesse momento de crise, o corpo deixa de funcionar como dado de identidade fixa e natural, lugar de delimitação e referência estável, para tornar-se a expressão da identificação pela mutação e pela performance”.

Na cultura digital, observa-se uma tendência de promover modificações no corpo (Featherstone: 1999; dentro outros mencionados anteriormente): desde as que implicam interferências sutis, obtidas em longo prazo com a utilização de cosméticos e a prática de ginástica; passando pelas permanentes como o bodybuilding, a tatuagem e o piercing - para estas duas, existem técnicas de remoção, embora não popularizadas --; até aquelas radicais como as cirurgias que promovem interferências profundas e irreversíveis. Tais práticas denunciam uma ênfase na visualidade do corpo.

Nos limites deste artigo, pretende-se estabelecer algumas aproximações possíveis entre corpo e embalagem, considerando os impactos das tecnologias no imaginário de corpo na publicidade - aqui entendida como produção cultural caudatária, isto é, que não cria, mas denuncia as concepções de mundo dos diferentes grupos para os quais é dirigida. Longe de considerar a publicidade ou a tecnologia como salvação ou perdição da sociedade pósmoderna, o que se intenta é apresentar uma breve discussão acerca de resignificações de corpo na sociedade de consumo.

A nova campanha publicitária das Sandálias Ipanema Gisele Bündchen, da Grendene -- produzida pela agência W/Brasil - constitui o corpus a ser analisado. O design também será objeto de algumas ponderações, na medida em que seu desenvolvimento afeta a criação publicitária e as reflexões quanto às áreas de atuação da comunicação de marcas, produtos e serviços 


\title{
Cultura: mistura e continuidade
}

A cultura se mantém e viceja numa complexa rede de significados, fluídica, permeável e repleta de veios que alimenta todos os nós e que garante a irrigação de todo o tecido social. Nada se perde em termos de significado na cultura, há sempre aproveitamentos, adaptações, transformações mais ou menos intensas. As produções culturais armazenam os significados, mas não de forma estagnada! Os significados são articulados uns com os outros e na interação são alimentados, modificados etc. Na complexa rede de significados da cultura, o novo e o velho coexistem. Por isso, entendemos que os significados que alicerçam as representações de corpo na publicidade têm heranças muito antigas. Caso contrário não teriam tanta força significativa.

Cultura é, portanto, mistura: bastante difundida, essa metáfora bem explicita a idéia de que nada se perde e de que há sempre uma proliferação de sentidos de cultura (Canclini; 1997). Conforme Santaella (2003: 14), "a cultura comporta-se sempre como um organismo vivo e, sobretudo, inteligente, com poderes de adaptação imprevisíveis e surpreendentes”. Ainda segundo a autora, as eras ou as formações culturais não são lineares, como se uma era precisasse desaparecer para que a próxima surgisse:

\begin{abstract}
ao contrário, há sempre um processo cumulativo de complexificação (...): Uma nova formação comunicativa e cultural vai se integrando na anterior, provocando nela reajustamentos e refuncionalizações. (...) Em cada período histórico, a cultura fica sob o domínio da técnica ou da tecnologia de comunicação mais recente. Contudo, esse domínio não é suficiente para asfixiar os princíp[ios semióticos que definem as formações culturais preexistentes (2003: 13-14).
\end{abstract}

$\mathrm{Na}$ atualidade, a julgar pelas re-significações presentes na publicidade, a tecnologia acena de forma otimista para a possibilidade de aprimoramento do corpo e até de superação das limitações impostas pela condição humana. $O$ binômio imperfeição-perfeição, revestido de diferentes linguagens, é recorrente nos imaginários mítico, religioso e médico. Observa-se uma interrelação entre eles, posto que os três recorrem à temática do transhumano e/ou 
do pós-humano. Hoje, coexistem noções de corpo de diferentes momentos históricos. Vale lembrar a metáfora da mistura.

Já desde a Grécia antiga, no período que se estende do pré-socrático ao helenismo, há mitos que se referem a criaturas que são uma mistura de humano e algo mais e que têm força e poder superiores ao do Homem. Seriam tais criaturas uma revelação de que, para os gregos, o corpo é imperfeito? Tal questões podem ser fundamentadas com as reflexões de Nietzsche em $O$ nascimento da tragédia ou helenismo e pessimismo (1992). Para ele, o homem grego, ao se distanciar dos mitos e fazer uso da razão, revela sua natureza trágica, ou seja, a insatisfação com a vida, com a natureza e com a natureza humana. Com Sócrates e Platão, aquela civilização atingiu o ápice de negatividade, posto que os dois filósofos desenvolveram uma reflexão a respeito da vida perfeita e do mundo ideal, respectivamente. O idealismo é, em certo sentido, a negação do mundo e suas imperfeições. Também na arte grega encontram-se evidências da idéia de imperfeição: a preocupação com a proporcionalidade, simetria e harmonia apontam para uma tentativa de correção da natureza (Duarte: 1997). Ao desenvolver tais conceitos buscam, por meio da razão, criar condições para a perfeição. Note-se a visualidade do corpo como aspecto relevante já desde a Grécia antiga.

No imaginário religioso cristão, encontra-se uma fundamentação bastante consistente para a concepção de corpo imperfeito. Na idade média, a igreja transforma o motivo intelectual do pesado original - um desafio intelectual a Deus - em carnal/sexual (Le Goff: 1994). O corpo passa a ser a instância em que o diabólico se manifesta. A imperfeição do corpo prejudica a alma: trata-se de representação carnal do pecado, que deve ser evitado, para que a alma alcance o paraíso e a vida eterna. $\mathrm{O}$ mal ou a imperfeição afetam a aparência do corpo, de modo que os males espirituais se manifestam na carne.

No imaginário médico, por sua vez, a idéia de imperfeição encontra-se associada à doença: o corpo doente carece de intervenção para voltar a ser 
saudável. Em outros termos, para a medicina, o corpo é um "vir a ser", ora porque precisa debelar a doença, ora porque pode ser submetido à ciência. A superação encontra-se na tanto na perspectiva de cura quanto na de poder transformador da ciência: a medicina científica tem o corpo como lugar de experimentação, pronto para superar os limites impostos pela condição humana.

Entenda-se por superação da condição humana uma transformação do corpo, ou seja, uma passagem do orgânico - humano -- para o inorgânico -pós-humano ou corpo-máquina --, dada a possibilidade de intervenção científica por meio da tecnologia. A doença e o envelhecimento, por exemplo, são faces da imperfeição, na medida em que revelam a fragilidade e temporalidade da carne. São representações da morte: o corpo em estado original caminha para o fim, mas o aprimoramento, alcançado por meio da ciência e da tecnologia, aponta para eliminação deste aspecto negativo. Eis as características da pós-modernidade: desmaterialidade e destemporalidade!

Na temática do pós-humano ou do transhumano, há referências míticoreligiosas que apontam para a superação dos limites corporais: "As fantasias de superação dos limites corporais, da ubiqüidade das subjetividades tecnológicas ou da digitalização do self, entre outras, apontam para um desejo de fuga de escape do tempo e do espaço" (Felinto: 2003).

Em que se fundamenta tal concepção de corpo? Segundo Lecourt (2003), o imaginário religioso fundamenta os discursos da inteligência artificial, o qual afeta a compreensão das relações possíveis entre ciência e corpo. As questões de biotecnologia sustentam duas correntes de interpretação do pós-humano, ou seja, a biotecnologia poderia fundamentar a desaparição do corpo orgânico a partir do desenvolvimento de um corpomáquina ou possibilitar o seu aprimoramento. Na primeira perspectiva, observa-se um horror ao corpo, noção difundida pelo imaginário religioso 
cristão, (Le Goff:1994; Lecourt:2003; Felinto: 2003 e 2005) e, na segunda, uma redenção do corpo pelo controle e correção dos males que o afetam.

\begin{abstract}
Este debate surge profundamente estruturado por duas grandes concepções teológicas cristãs acerca da situação do homem no mundo. (...) Um milenarismo otimista da grande restauração com uma esperança de redenção opõe-se a um milenarismo apocalíptico que só timidamente deixa perceber uma esperança de ressurreição (Lecourt: p.71)
\end{abstract}

O imaginário tecnocultural que se expressa na publicidade é alicerçado pela idéia, recorrente na cultura ocidental, de que é possível superar a condição humana, alterando as relações corpo-tempo e corpo-forma. Trata-se de uma visão otimista quanto ao uso da biotecnologia como um conhecimento que pode aperfeiçoar o corpo por meio da tecnologia.

A publicidade anuncia a superação do tempo. O corpo como embalagem não sofre sua ação e permanece inalterado na "aparência jovem". Observa-se na imagem de corpo um "vir a ser”. Dada sua condição mortal, faz sentido concebê-lo como algo por fazer, ou seja, algo que pode sofrer intervenções. Nesse sentido, prolongar a vida ou aprimorar o corpo consiste na tentativa de adiar a morte.

O produto faz apologia à eterna juventude. Dentre os inúmeros produtos que se assemelham nas vitrines e nas mensagens publicitárias, destaca-se aquele que tiver a embalagem mais vistosa e atual. Há sempre alguma novidade. A acentuada preocupação com o design das embalagens caracteriza o atual estágio do mercado: visibilidade é o que se espera, posto que já não há diferenças significativas quanto à matéria-prima, à tecnológica $\mathrm{e}$ à performance dos produtos. Assim, despertar o interesse do olhar do consumidor num mercado sobrecarregado de visualidade é façanha da embalagem.

No entanto, a imagem implica ausência do objeto: ao enunciar o produto por meio da visualidade, o corpo pode reduzir-se na sua complexidade multifacetada. Segundo Baitello (2002: 33), "a transferência 
das vivências do corpo para o mundo das imagens significa também sua transferência para um tempo in effigie, congelado em um eterno presente e, portanto, sem presente".

Vale citar, aqui, as palavras de Kamper, a partir de Baitello (2002: 35): “ver permanece superficial. A profundidade do mundo não é para o olho. E quando o olhar penetra, apenas aumentam novamente as superfícies e as superficialidades. A era óptica já o provou ex negatio”. Ou seja, o corpo embalagem na campanha das Sandálias Ipanema Gisele Bündchen, da Grendene, produz visibilidade para o produto, mas também produz uma invisibilidade para a nudez da top model. A plasticidade da embalagem parece enfraquecer as dimensões biofísicas e culturais do corpo. Trata-se de um corpo que se transformou em imagem: daí sua visualidade exacerbada.

\section{Embalagem e palimpsestos: breves aproximações}

A noção de corpo impregnada de visualidade sugere uma analogia entre embalagem e palimpsesto, salvaguardadas as devidas diferenças históricas e funcionais que os reveste. Segundo Cauduro (2004:53), o palimpsesto é um documento/suporte sobre cuja superfície muitos textos foram escritos e na qual ainda permanecem os "traços visíveis, imperfeitamente apagados de escritos anteriores, que se constituem em importante fonte de recuperação de obras literárias perdidas da Antigüidade clássica”. O termo "palimpsesto" significa "raspado de novo" em grego. Pode ser entendido como um "pergaminho reciclado" ( 2004:55).

O corpo embalagem da campanha das sandálias Ipanema, da Grendene, faz alusão ao palimpsesto. O corpo da top model é re-escrito com um novo texto: uma vez apagado o texto da nudez, escreve-se um outro: o da cultura brasileira, tomando a fauna e a flora como paradigmas. Os elementos combinam-se de forma anárquica: são fragmentos da cultura - aves; plantas; insetos que se misturam ao acaso. O resultado é a soma de tudo: uma mistura que representa o Brasil e remete ao slogan do produto. 
Não é por acaso que na pós-modernidade a estética do palimpsesto tem lugar privilegiado nas artes e no design. "Eles se alimentam da anarquia, da fragmentação, da instabilidade, da heterogeneidade, da reciclagem de memórias e textos descontextualizados, descontínuos - traços típicos da escrita palimpséstica” (2004:57). No corpo embalagem da referida campanha, observa-se a mesma estética visual: há uma certa desconstrução da cultura ao fragmentá-la para apresentar alguns de seus elementos constitutivos. Imbricam-se muitos textos naquele produzido como pele de cultura no corpo da top model: assim, não se pode dominar o sentido de um texto, porque cada texto ali presente aponta para muitas possibilidades de leitura.

Apenas para exemplificar, o texto-tatuagem, produzido a partir de elementos da fauna e flora brasileiras, representa a cultura do Brasil, mas também o corpo da top model, restos de um texto que permanece significando, pode representar o Brasil. Por sua vez, cada leitor/receptor da campanha poderá interpretá-la conforme suas competências de leitura e as referências de cada elemento empregado. Os traços típicos da escrita palimpséstica encontram-se bastante realçados: Trata-se de um texto que remete a outros; de um texto que traz as marcas de outros, impregnadas no suporte.

\section{Traços do imaginário do consumo e consumo do corpo}

Imagem de corpo é imagem de produto: portanto, embalagem! Visualidade que confere visibilidade. Imagem que se consome: nesse sentido, há um consumo do corpo: "a realidade se torna cada vez mais virtual, enquanto a identidade do sujeito é considerada agora imaginária, plural, contraditória e cambiante" (Cauduro; 2004: 47).

Os corpos embalagem mantêm-se por algum tempo em exibição, já que a necessidade de visibilidade requer sempre novos investimentos/revisões de imagem. Tal como acontece com os produtos que, ao cumprirem seu ciclo de vida mercadológico, são substituídos por outros, o design das embalagens 
também é substituído. A velocidade com que a exposição gera invisibilidade gera demanda por novos corpos. Há uma obsessão pela novidade: corpos aparecem e desaparecem, sem que haja diferenças substanciais entre eles, o que se assemelha - guardadas as diferenças quanto à finalidade da comunicação - à busca incansável do corpo/imagem perfeito. É preciso sempre superar a imagem e a embalagem anterior.

Se a pós-modernidade equivale à sociedade do consumo, é mister observá-la a partir do consumo: características como "desmaterialidade"; "desreferencialidade"; "destotalidade" e "destemporalidade” são categorias gerais da época atual. Como pensar seus impactos num imaginário do consumo?

Entendendo embalagem como imagem, pode-se considerar, num primeiro momento de reflexão, que o imaginário do consumo apresente dois traços que se destacam: (1) a desmaterialidade, posto que o valor da marca sobrepõe-se ao valor da matéria-prima e/ou da mão-de-obra de produção. Nesse sentido, o consumidor não compra o produto; mas as associações construídas entre produto e a realidade do consumidor. E (2) a destemporalidade, uma vez que o produto passa por ciclos de vida que o mantém em permanente presente ou "estado de juventude" e também porque o produto ganha re-significações a cada operação de atualização ou simples reforço.

Quando a visualidade do corpo torna-se aspecto preponderante, é possível considerar que o consumo tornou-se uma atividade de fruição estética de imagens. Antes de comprarmos produtos, compramos embalagem: formas, cores e texturas. Nesse sentido, o consumo de imagens fundamenta a experiência do produto e também a de corpo. 


\section{Referências:}

BAITELLO JR., Norval. O olho do furacão. A cultura da imagem e a crise da visibilidade. In: MOTTA, Luiz et al. (orgs.). Estratégias e culturas da comunicação. Brasília: Editora Universidade de Brasília, 2002.

CANCLINI, Nestor Garcia. Culturas Híbridas: estratégias para entrar e sair da modernidade. São Paulo: UNESP, 1997.

CAUDURO, Flávio Vinicius. "Design gráfico \& pós-modernidade”. In: MARTINS, Francisco Menezes \& MACHADO, Juremir (orgs.). A Genealogia do Virtual: comunicação, cultura e tecnologias do imaginário. Porto Alegre: Sulina, 2004.

DUARTE, Rodrigo (org. e sel.). O Belo autônomo: textos clássicos de estética. Belo Horizonte: UFMG, 1997.

FELINTO, Erick. "Transhumanismo e mito: notas sobre o culto do ciborgue", in Cunha, Paulo \& Lemos, André (orgs.).Olhares sobre a Cibercultura. Porto Alegre: Sulina, 2003.

. A religião das máquinas: ensaios sobre o imaginário da cibercultura. Porto Alegre: Sulina, 2005.

GARCIA, Wilton. Corpo, mídia e representação: estudos contemporâneos. São Paulo: Pioneira Thonson, 2005.

LECOUT, Dominique. Humano e pós-humano. Lisboa: Edições 70, 2003.

LE GOFF, Jacques. O imaginário medieval. Lisboa: Editorial Estampa, 1994.

LEMOS, André. Cibercultura: Tecnologia e vida social na cultura contemporânea. Porto Alegre: Sulina, 2002.

LIPOVETSKY, Gilles. Sedução, publicidade e pós-modernidade. In: MARTINS, Francisco Menezes \& MACHADO, Juremir (orgs.). A Genealogia do Virtual: comunicação, cultura e tecnologias do imaginário. Porto Alegre: Sulina, 2004.

NIETZSCHE, Friedrich. O nascimento da tragédia ou helenismo e pessimismo. São Paulo: Companhia das Letras, 1992.

SANTAELLA, Lúcia. Culturas e artes do Pós-humano. São Paulo: Paulus, 2003. 